\section{FRACTURE OF PENIS}

\section{Maj PS BHANDARI ${ }^{*}$, Lt Col PS GARCHA ${ }^{+}$}

MJAFI 1998; 54 : 157-158

KEYWORDS : Fracture of penis; Urethral injury.

\section{Introduction}

$\mathbf{F}$ racture of penis is uncommon, only about 200 cases having been reported in the world literature $[1,2]$. Injury is most often due to the erect organ being forcibly bent downwards during coitus or other sexual practices. Following trauma, the erect organ suddenly becomes flaccid. The extravasation of blood, which is considerable, causes intense pain and swelling. Early surgery involving incision, clearing out of blood clot and suture of ruptured corpus cavernosum has yielded good results [3]. A case of fracture of penis without injury to the urethra is reported.

\section{Case Report}

A 23-year-old individual reported with severe pain and swelling of penis. He gave history of vigorous sexual intercourse under the influence of alcohol and having accidentally struck the wife's thigh with the penis. Immediately he heard a crackling sound associated with excruciating pain, swelling and flaccidity of the organ. He had one normal micturition just before reaching the hospital. Examination revealed a swollen, flaccid, extremely tender organ, which was deviated to left side (Fig I).

Exploration was done within 3 hours of sustaining the injury. Large subcutancous haematoma was evacuated under general anaesthesia and tears of tunica albuginea of corpus cavernosum was repaired. Postoperatively he received antibiotics and non steroid anti-inflammatory drugs. On review 4 months later the patient had normal erectile function with no residual deformity (Fig 2).

\section{Discussion}

Fracture of the erect penis is a rare but a well documented penile injury. In Central Africa the condition is well known, for women had learned that an effective method of preventing rape is to take a firm hold of the penis and sharply bend it backward towards the anus [4]. In most cases the injury is either self inflicted, reportedly in an attempt to relieve prolonged erection, or occurs during coitus [5], as was the case in this patient.

The organ suddenly becomes flaccid, and excruciating pain is followed by great swelling from extravasated blood. Such trauma to the erect penis can also cause rupture of the anterior urethra and corpus spongiosum.

The condition should be treated by immediate operation. Through a suitable incision, clot are turned out and the corpora cavernosa repaired with sutures. This policy has been claimed to reduce the incidence of penile deformity. Others have managed fractures of penis without surgical intervention, but the prolonged hospitalisation and a higher rate of complications have prompted the universal acceptance of an early surgical intervention $[1,6]$.

In case of suspected rupture of the urethra, retrograde urethrography is advisable to define the extent

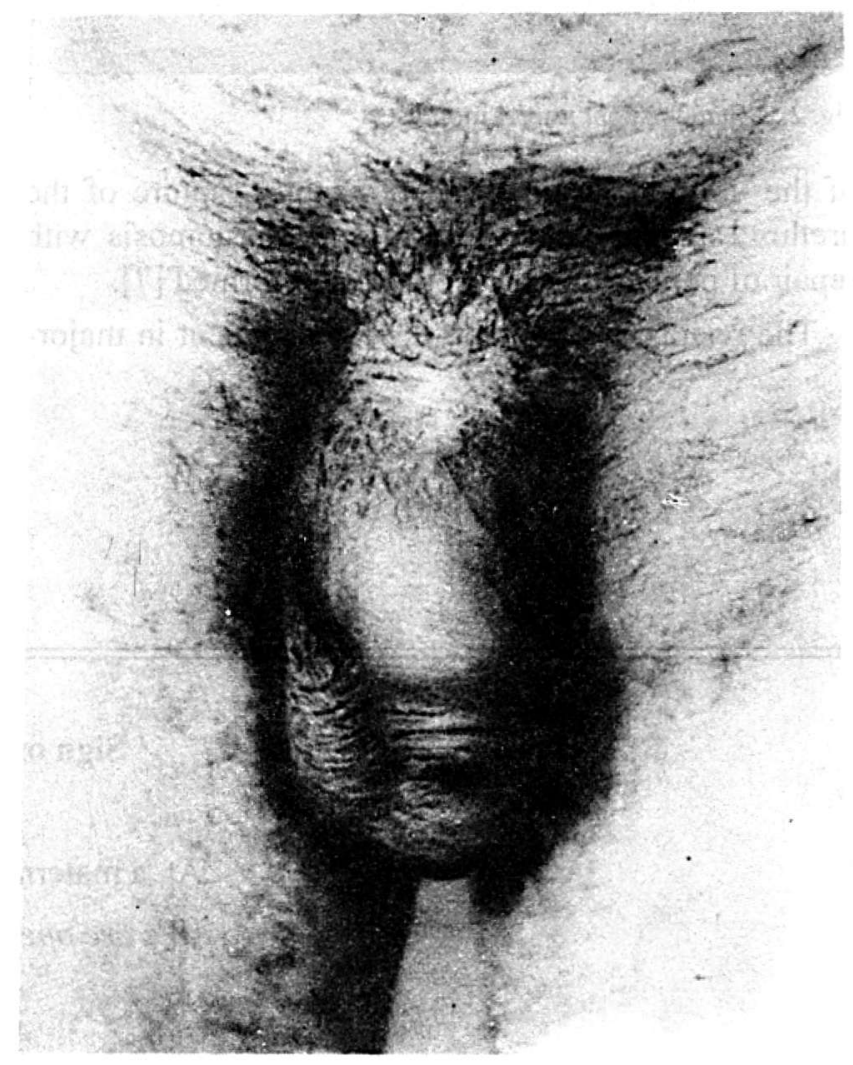

Fig. 1: Photograph showing a swollen. flaccid penis which is deviated to left side. 


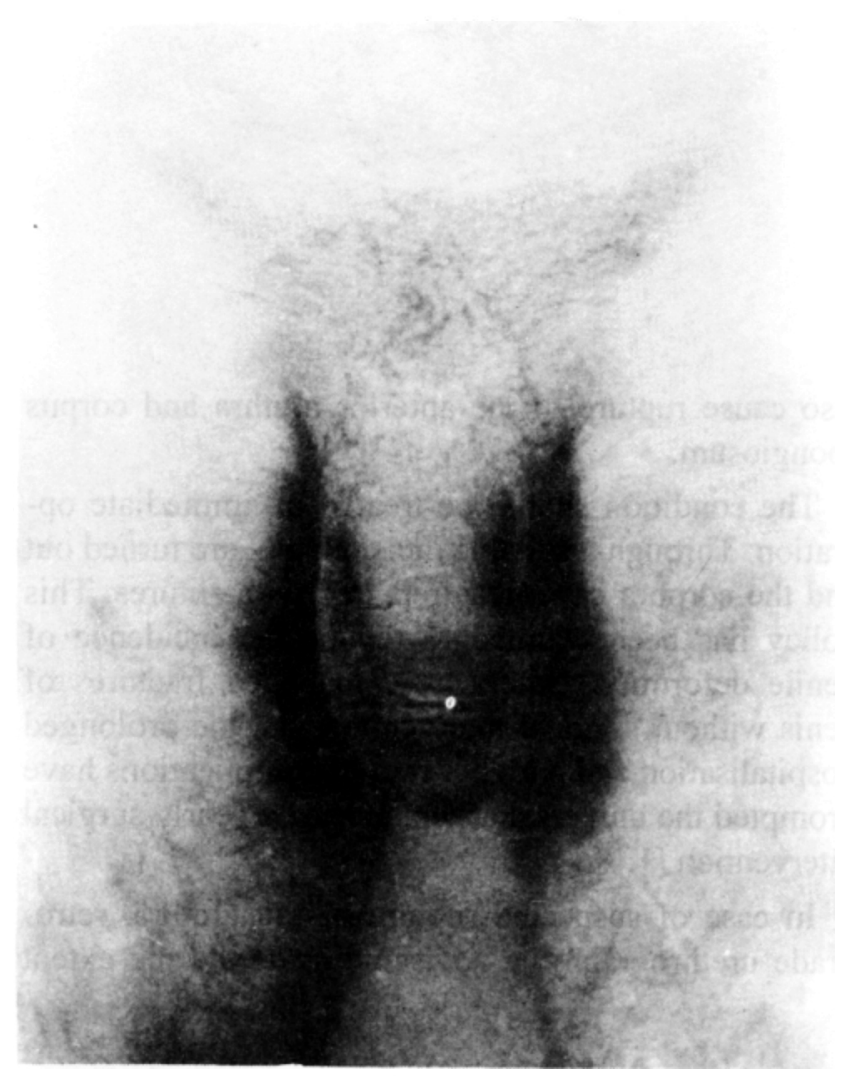

Fig. 2 : Same patient after 4 months.

of the urethral lesion. If there is total rupture of the urethra, an emergency end to end anastomosis with repair of penile fracture should be performed [7].

The results of early surgery are excellent in major- ity of cases. Suboptimal erection, residual chordee, fibrotic nodule and stricture of urethra have been described when surgery is delayed or when a conservative approach is adopted $[8,9]$. It is therefore emphasized that early and prompt surgical intervention be undertaker: with a view to early recovery and to minimise residual complications [1].

\section{REFERENCES}

1. Singh DJ. Fracture penis with injury to the erectile tissue. Ind J Surg 1996; 58: 107-9.

2. Mbonu OO, Aghaji AE. Fracture of the penis in Emegu, Nigeria. JR Coll Surg Edinb 1992: 37(5): 309-10.

3. Tiptaft RC, David Mee A. The urethra and penis. In: Harding Rains AJ, Charles VM, editors. Bailey and Love's Short Practice of surgery. 20th ed. London: IIK Lewis and Company Ltd. 1988; 60: 1320-51.

4. Mitchell JP. The penis, testis and scrotum. In: Hugh Dudley $A F$, editor. Hamilton Bailey's Emergency Surgery; 11 th ed. Bristol : John Wreight and Sons Ltd. 1986: 51: 534-42.

5. Goh HS, Trapnell JE. Fracture of the penis. Br J Surg 1980; 67: 680

6. Gross M, Arnold TL, Waterhouse K. Fracture of the penis : rationale of surgical management. J Urol 1971: 106: 708-10.

7. Walton JK. Fracture of the penis with laceration of urethra. Br J Urol 1979; 51: 308-9.

8. Mearse EM. Traumatic rupture of the corpus cavernosum. J Urol 1971; 105: 407-8.

9. Pendse AK, Mewara PC. Babel AL, Jain NP. Erectile tissue injuries of the penis related to sexual practices. Ind I Surg 1983; 45: 484-6. 